\title{
Evolutionary preferences for physical formidability in leaders
}

\author{
Gregg R. Murray \\ Department of Political Science \\ Texas Tech University \\ 10 Holden Hall \\ Lubbock, TX 79409-1015 \\ g.murray@ttu.edu
}

\begin{abstract}
This research uses evolutionary theory to evaluate followers' preferences for physically formidable leaders and to identify conditions that stimulate those preferences. It employs a population-based survey experiment $(N \geq 760)$, which offers the advantages to internal validity of experiments and external validity of a highly heterogeneous sample drawn from a nationally representative subject pool. The theoretical argument proffered here is followers tend to prefer leaders with greater physical formidability because of evolutionary adaptations derived from humans' violent ancestral environment. In this environment, individuals who allied with and ultimately followed physically powerful partners were more likely to acquire and retain important resources necessary for survival and reproduction because the presence of the physically powerful partner cued opponents to avoid a challenge for the resources or risk a costly confrontation. This argument suggests and the results indicate that threatening (war) and nonthreatening (peace, cooperation, and control) stimuli differentially motivate preferences for physically formidable leaders. In particular, the findings suggest threatening conditions lead to preferences for leaders with more powerful physical attributes, both anthropometric (i.e., weight, height, and body mass index) and perceptual (i.e., attributes of being "physically imposing or intimidating" and "physically strong"). Overall, this research offers a theoretical framework from which to understand this otherwise seemingly irrational phenomenon. Further, it advances the emerging but long-neglected investigation of biological effects on political behavior and has implications for a fundamental process in democratic society, leader selection.
\end{abstract}

Key words: Leaders, followers, evolutionary theory, formidability, resource holding potential

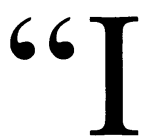

deal" citizens and political sophisticates scoff at the idea that a candidate's physical appearance could affect the likelihood that people will vote for that person, but substantial evidence suggests this is the case. Individuals heavily rely on heuristics in political decision making ${ }^{1}$, including using heuristics associated with the physical characteristics of candidates when voting. Lau and Redlawsk ${ }^{2}$ identify candidate appearance as "possibly the most important (or at least most frequently employed)" political heuristic. They conclude this because visual images are ubiquitous in the social and political worlds and because they convey vast amounts

doi: 10.2990/33_1_33 of information and evoke social stereotypes and emotions. Evidence suggests individuals infer information that predicts election outcomes with as little as one second of exposure to a candidate's image. ${ }^{3}$ Researchers have found evaluations of political leaders and election outcomes can be predicted with physical attributes of leaders such as attractiveness, $4,5,6,7,8,9$ "looking the part" (e.g., competence), $3,8,9,10,11$ votercandidate facial similarity, ${ }^{12}$ masculinity-femininity, ${ }^{13,14}$ vocal communications, ${ }^{15,16,17}$ obesity, ${ }^{18}$ height, ${ }^{19,20,21}$ sex, ${ }^{22,23}$ and skin color. ${ }^{24}$

Some scholars explain these effects by concluding physical features prime elements of modern leadership prototypes such as competence, intelligence, and leadership skills. ${ }^{25}$ Others suggest they reflect the influence 
of evolutionary forces on leader preferences. ${ }^{26,27}$ In support of this position, candidate appearance effects have been found cross-culturally, ${ }^{13,28,29,30,31}$ in children, ${ }^{32}$ and neurologically. ${ }^{31,33}$ These cross-cultural, developmental, and biological findings suggest responses to candidate appearance are not solely idiosyncratically transmitted through learned cultural practices, as suggested by the standard social science model, ${ }^{34}$ but may also be stimulated by universal forces derived from human evolution. ${ }^{35}$

Following this line of argumentation, this study offers an explanation for the phenomenon of follower preferences for physically formidable leaders based on the evolutionary theory of natural selection. ${ }^{36}$ Research shows that individuals imagine or ideate national leaders who are taller than the typical citizen, ${ }^{19}$ and election outcomes in the United States substantiate a height-leader connection. ${ }^{21}$ For example, the tallest of the two United States major-party candidates from 1789 to 2012 won in 58 percent of presidential elections and received the majority of the popular vote in 67 percent of those elections. Moreover, all pairs of major-party presidential nominees held a substantial height advantage over the typical male citizen to the point that even the shortest nominees for each election year as a group held a substantial height advantage over the typical male citizen. ${ }^{37}$

Darwin's theory of natural selection ${ }^{36}$ can provide an analytical lens through which to understand this phenomenon. Evidence suggests the evolutionary environment for ancestral humans was violent as individuals competed with others inside and outside their group, including nonhuman predators, for resources to survive and reproduce. ${ }^{38,39,40,41,42,43}$ These evolutionary resources included physical assets such as hunting territory and mates as well as psychological resources, most likely related to social esteem, such as vengeance and belligerence. ${ }^{39}$ Because aggressors wanted to reduce the risk of harm to themselves, much of the violence targeted weak and defenseless opponents who could not effectively repulse an attack. ${ }^{39}$ Individuals who partnered with more physically formidable allies benefitted from the physical prowess signaled by their ally to potential challengers. Challengers knew the powerful ally would likely join in any confrontation and increase the challenger's potential costs of confrontation as well as reduce the challenger's probability of success. ${ }^{44,45,46}$ As such, individuals with physically powerful allies were more likely to survive and reproduce, because they were less likely to be challenged for important resources. ${ }^{46}$ Physically powerful allies could readily become leaders because providing physical protection was a costly but remunerated behavior. By providing protection, the physically formidable ally could increase access to important survival and reproductive resources by signaling desirable qualities to attract other allies ${ }^{47}$ (and mates) and/or exchanging this service for prestige bestowed by an ally or allies including deference to the powerful ally's decisions. ${ }^{48}$ Given that human evolution is measured in millennia ${ }^{49}$ this mismatched preference ${ }^{50}$ for physically formidable leaders persists today even though modern leaders are extremely unlikely to engage in physical combat on behalf of their followers. ${ }^{42}$

This brief review suggests that threatening and nonthreatening stimuli should differentially motivate preferences for physically formidable leaders via evolutionary psychological mechanisms such that threatening conditions lead to preferences for leaders with greater physical formidability. In an effort to assess this evolutionary argument, this article next provides the theoretical bases for the expectation that followers have a preference for more physically formidable leaders. The next section details the conduct and results of the population-based survey experiment that uses a highly heterogeneous subject pool drawn from a nationally representative sample $(N$ $\geq 760$ ), which, therefore, accrues benefits to both the internal and external validity of the study. The results detailed in the following section suggest, consistent with the evolutionary argument presented here, that threat stimulates a preference for more physically formidable leaders. The final section puts the results in context and presents possibilities for future advances in this literature. More broadly, this research sheds light on one of the key processes in a democracy, leader selection. Moreover, it proffers a theoretical basis for understanding this seemingly irrational behavior, and it contributes to the growing but long-neglected investigation of biological effects on political behavior.

\section{Evolution and leadership}

Evolution shapes humans with traits that promote survival and reproductive success in the course of their interactions with their social and physical environ- 


\section{Physical formidability}

ments. ${ }^{36}$ These traits can be physical and psychological (i.e., cognitive, emotional, and motivational). ${ }^{49,51}$ Because the speed of human evolution is counted in millennia, ${ }^{49}$ modern humans still possess instincts of hominids living in the human environment of evolutionary adaptedness or EEA. ${ }^{34,52}$ The human EEA is the scientifically informed reconstructions or statistical composite of the ancestral conditions in and selection pressures under which humans evolved. ${ }^{52,53}$ Evolutionary instincts can seem irrational in, or "mismatched" to, the modern context and, in the worst cases of evolutionary mismatch, be maladaptive. ${ }^{50}$ For instance, changes in food acquisition from hunting-gathering to agricultural production have resulted in greater consumption of carbohydrates and saturated fats, which are associated with illnesses related to diet such as cardiovascular disease and diabetes mellitus. ${ }^{54,55}$ Similarly, neurobiological systems that evolved in hunter-gatherers to regulate risk decisions involving immediate and tangible consequences for survival and reproduction, such as food acquisition, can result in pathological gambling in the modern casino gaming context of abstract currency and delayed losses, such as the symbolic value of chips and chip counts. ${ }^{56}$

Applying this logic to leadership-followership, scholars have argued that modern preferences for traits in leaders can be affected by solutions that evolved during the evolutionary environment. ${ }^{27,41,57}$ That is, contemporary humans discount elements of modern, large-scale society, such as high population density and complex bureaucracy, and use cues to effective leadership that were employed by ancestral humans in evolutionary, small-scale societies. Evolutionary societies most likely consisted of smaller groups of 10 to 30 individuals, who cohered for daily living activities such as foraging, reproduction, and exploring, that were loosely connected to larger groups of 150 to 500 individuals who shared a common culture or communication method. ${ }^{41,52,58}$ Group hierarchies occurred naturally, but coalitions of subordinates kept leading members in line using criticism, ridicule, ostracism, and, in extreme cases, execution. ${ }^{59}$ Predation by animals and conflict within and between groups was common as individuals and groups competed for land, food, and status. ${ }^{38,39,40,41,42,43,60}$ Groups with leaders were more likely to survive in ancestral times because leaders provided evolutionary benefits to followers by coordinating group movement, keeping peace within the group, and leading activities against competing groups. ${ }^{41}$ In particular, group leadership often required physical prowess as leaders were frequently called on to lead group hunts, quell fights within the group, and organize raids against other groups. ${ }^{42}$ Because so many leadership domains in ancestral history required physical strength and stamina, human ancestors most likely valued indicators of physical fitness such as height, weight, energy, and health. ${ }^{42}$ For instance, Chagnon ${ }^{38}$ reported that traditional societies that experienced a great deal of group conflict were often led by individuals characterized as fierce warriors.

The preferences of modern followers reflect these evolutionary factors via several connections. First, people quickly create enduring dominance hierarchies, at times on a "first-glance" basis, that form prior to any verbal exchange. ${ }^{61}$ In particular, individuals can visually gauge others' physical formidability in terms of strength and fighting skills. ${ }^{62}$ This ability is most likely based on the nontrivial correlation between strength and fighting skills ${ }^{60}$ and the efficacy of height as an "honest" or reliable signal ${ }^{63}$ for strength and fighting skills. ${ }^{62}$ Further, followers tend to favor more dominant leaders under conditions of threat. ${ }^{13,64,65}$ This comports with evidence that persons with greater relative height are perceived as more capable and competent ${ }^{66}$ and further evidence that people with greater physical stature are more respected and feared by potential opponents. ${ }^{67,68} \mathrm{It}$ is reasonable to conclude these psychological tendencies can affect individual behavior in modern intra- and intergroup competition. For instance, people tend to prefer economic and political allies with greater physical stature ${ }^{69}$ as well as leaders with greater physical stature. ${ }^{19,20,21,70,71}$ These tendencies are consistent with primate research showing the social rank of a group member is related to the social rank of that individual's allies. This dependent rank theory asserts that individual group members know a powerful member will support an ally in a fight and, therefore, anticipate the probable outcome of the fight. So the powerful ally's presence signals the adversary to submit to the ally or withdraw before the fight commences. ${ }^{44}$ 


\section{Physical stature and leadership}

There is substantial empirical evidence to support the link between physical formidability and leadership attainment. The evidence comes from a diversity of contexts and fields including anthropology, economics, nonhuman animal behavior, and psychology. Formidability is defined as the potential to hold resources by imposing costs on challengers. ${ }^{62}$ Generally speaking, size is an effective indicator of fighting ability, ${ }^{60,72}$ such that larger animals are more likely to win physical contests. ${ }^{73}$ Smaller competitors often lose contests because larger competitors, who have greater resource holding potential (RHP) due to their greater fighting ability, are able to impose relatively greater costs on them. ${ }^{46}$ As such, individuals commonly use physical size as an indicator of $\mathrm{RHP}^{73}$ and compare their size to a competitor's in an effort to assess relative RHP and avoid contests in which costs are expected to be too high. ${ }^{45,67,74}$ Unsurprisingly, then, when communicating aggression to an individual competitor or group of competitors, nonhuman animals frequently display dominance in ways that exaggerate their size. ${ }^{72}$ In evolutionary terms, ancestors who chose physically formidable allies were more likely to survive and reproduce, because potential challengers received a signal about the probable negative outcome of a physical conflict. ${ }^{46}$ This signal was particularly strong because physical stature was a widely available, quick, and effective indicator of RHP. ${ }^{62,75}$

Research regarding nonhuman animal behavior demonstrates a positive relationship between social rank and physical size. For instance, the great apes, African elephants and Red Deer, and varieties of ants, birds, and fish manifest this relationship. ${ }^{76,77,78,79,80,81}$ This research suggests size acts as a cue for strength when nonhuman animals encounter a fight-or-flight decision under conditions of conflict. ${ }^{82}$

Millennia-old anthropological evidence suggests there was a tendency in human groups, as well as nonhuman animal groups, for social status and rank to be associated with physical stature. ${ }^{83}$ For instance, Boix and Rosenbluth ${ }^{84}$ find physical height is associated with greater political and economic power in early huntergatherer and Egyptian societies as well as modern European Monarchies. Angel ${ }^{85}$ and Haviland ${ }^{86}$ found a strong positive correlation between physical stature and "political control" among skeletal remains of pre-
Classical Greeks and Mayans. This is also consistent with studies of modern humans. There is evidence of a cognitive foundation to the relationship. Words such as "high," "top," and "up" are associated with greater power, and greater power is associated with positions nearer the top of an image (e.g., higher boxes on an organizational chart). ${ }^{87}$ Similarly, objects imprinted with symbols indicating greater value are perceived as being physically larger than identically sized objects imprinted with symbols of lesser value. ${ }^{8,89}$ Preverbal infants (10-13 months old) have been shown to demonstrate a size-status relationship by assigning greater social dominance to the larger of two anthropomorphized, animated blocks confronting each other over a physical location. ${ }^{90}$

In further evidence of symbolic effects, subjects primed with information about the successes of terrorists estimate that a nonspecified terrorist is physically larger and stronger, while subjects primed with information about the failures of terrorists (e.g., the killing of Osama bin Laden) estimate that a nonspecified terrorist is physically smaller and weaker. ${ }^{91}$ Analogously, evidence suggests nonverbal cues that increase the social status of an individual accomplish this by altering perceptions (increasing) of the person's size. ${ }^{92}$ Humans to whom higher authority status is imputed are viewed as taller than their actual height ${ }^{93,94,95}$ and, conversely, people impute higher professional status to taller individuals. ${ }^{96,97}$ This comports with findings that shorter men are more likely to do physically demanding work, while taller men are more likely to do sedentary work. ${ }^{98}$ Further evidence suggests taller males achieve higher levels of educational and professional success. ${ }^{99,100,101,102}$

Finally, leadership research suggests there are several commonly held modern leadership prototypes (e.g., charisma, competence, dedication, integrity, intelligence, leadership, reliability, and sensitivity), ${ }^{103,104,105}$ and evidence suggests physical attributes may prime elements of these prototypical traits. ${ }^{25}$ In line with this perspective, research indicates height positively impacts the perception of leadership, ${ }^{70,71}$ and physical stature influences the selection of corporate and government executives. ${ }^{106}$ In the political context specifically, perceptions of a candidate's height depend on voters' preferences regarding that candidate. ${ }^{20}$ Further, winners of political elections are viewed as being taller after their victory than before, ${ }^{20,107}$ and 


\section{Physical formidability}

Table 1. Treatments and balance, in percentages

\begin{tabular}{lcccccccc}
\hline \hline Treatments & $N$ & Female & Mean Age & Ideology (liberal) & Income & Race (white) & HS Grad & News interest \\
\hline War & 227 & 51.0 & 51.6 & 30.8 & 40.6 & 72.8 & 24.6 & 55.8 \\
Peace & 254 & 56.0 & 52.4 & 33.1 & 42.1 & 74.4 & 25.6 & 54.3 \\
Cooperation & 261 & 53.0 & 52.6 & 30.4 & 46.2 & 73.5 & 33.1 & 52.3 \\
Control & 258 & 53.0 & 52.4 & 31.8 & 41.5 & 74.0 & 27.1 & 55.0 \\
$\chi^{2}(p$-value, two-tailed) & 0.81 & - & 0.91 & 0.82 & 0.49 & 0.47 & 0.75 \\
$F(p$-value, two-tailed $)$ & - & 0.80 & - & - & - & - \\
\hline
\end{tabular}

followers describe their ideal national leader as being taller than the typical citizen of their country. ${ }^{19}$

In summary, this line of argumentation leads to the expectation that modern followers prefer leaders with greater physical stature under conditions of threat due to a psychological mechanism that evolved in response to the violent environment ancestral humans endured. If this perspective is correct, then threatening stimuli should trigger a preference for leaders with greater physical stature. The experimental study described in the next section tests this assertion.

\section{Data and methods}

The experiment was fielded as part of the 2012 Cooperative Congressional Elections Study (CCES). The CCES is an ongoing series of online surveys administered to a nationally stratified sample by YouGov/Polimetrix. The firm nonrandomly recruits large numbers of volunteer respondents from which it uses proximity matching to the American Community Survey (in this case the 2008 survey) conducted by the U.S. Census Bureau to construct a representative sample of adults in the United States. The survey was administered before and after the 2012 presidential election and consisted of two parts: a common section of questions asked of 54,535 respondents and team modules administered to subsamples of 1,000 respondents. This research is based on questions in the common and team content modules that were administered in the pre-election wave. The result is a highly heterogeneous experimental subject pool $(N \geq 760)$ drawn from a nationally representative populationbased survey that enjoys the advantages of experimentation for the internal validity of the study and a nationally representative sample for external validity. ${ }^{108}$ See Appendix A for information on the subject pool. Overall, compared to reports by the Census Bureau, ${ }^{109}$ the experimental subject pool appears to be slightly more female ( 52.8 percent in the subject pool versus 50.8 percent reported by the Census), slightly more racially diverse (white/Caucasian: 73.1 percent versus 77.7 percent), similar in terms of wealth (median income of $\$ 50,000$ to $\$ 59,999$ versus median of $\$ 53,046)$, less Hispanic (8.3 percent versus 17.1 percent), and more educated (34.9 percent college graduates versus 28.5 percent).

\section{Design}

Subjects were randomly assigned by the survey system to one of four experimental groups using simple random assignment. The treatments consisted of vignettes asking subjects to ideate the national leader they would like to lead their country under conditions of war, peace, a crisis requiring nationwide cooperation to overcome, or a control condition that provides no contextual information. The war condition was designed to serve as the threat condition, while the peace, cooperation, and control conditions were designed to serve as the nonthreat conditions. The complete vignettes appear in Appendix B. Following treatment, subjects were asked to describe in words their ideated leader and then to answer a number of closed-ended questions regarding their leadership preferences.

Random assignment to experimental groups is intended to make the groups statistically equivalent so that any differences in outcomes between the groups are attributable to the treatments. A statistically significant $\chi^{2}$ test of a multinomial logit model in which group assignment is regressed on subject gender and age and series of indicator variables for political ideology, family income, race, education, and news interest indicates the randomization process did not generate statistically equivalent experimental groups $\left(\chi^{2}(114)=709.46, p<0.001\right)$. Table 1 provides further details on group equivalency. Despite the statistically significant multinomial regression model, none of the tests of the joint distributions of the covariates 
indicates statistical imbalances among the treatment groups. Nonetheless, the analyses will be conducted using multivariate regression to account for potentially biasing imbalances.

\section{Manipulation check}

Tests indicate the treatments successfully manipulated subjects' assessment of the relative threat posed by the war, peace, and control vignettes and the relative cooperation required by the cooperation and control vignettes. Subjects in the war, peace, and control groups were asked this post-treatment question: "How dangerous in terms of your country's long-term survival is the situation facing the preferred leader you just described?" Subjects in the cooperation group were not asked this question, because there was no intention to stimulate a threat response in the cooperation treatment. The response set ranged from 1 for "not at all dangerous" to 7 for "very dangerous." The mean score for subjects treated with the war vignette was 4.6 $(S D=1.6)$. The mean score for subjects treated with the peace vignette was $3.8(S D=1.7)$, while the mean score for the subjects treated with the control vignette was $4.4(S D=1.7)$. The difference in means between the war and peace vignettes achieves conventional levels of statistical significance ( $p<0.001$, one-tailed), while the difference between the war and control vignettes approaches conventional levels of statistical significance ( $p=0.10$, one-tailed).

Similarly, subjects in the cooperation and control groups were asked this post-treatment question: "As indicated above, how much cooperation do the citizens of your country need to give the preferred leader you just described?" Subjects in the war and peace groups were not asked this question because there was no intention to stimulate a cooperation response in those treatments. The response set ranged from 1 for "not much cooperation" to 7 for "a great deal of cooperation." The mean score for subjects treated with the cooperation vignette was $5.9(S D=1.2)$, while the mean score for the subjects treated with the control vignette was $5.7(S D=1.3)$. The difference between the cooperation and control vignette achieved conventional levels of statistical significance ( $p=0.02$, one-tailed).

\section{Data analysis}

Due to possible imbalances in group assignment, the tests are conducted using multivariate regression to control for factors other than the treatments that might influence the outcomes. All models are estimated using OLS regression due to the continuous nature of the dependent variables and robust standard errors due to evidence of heteroskedasticity. Descriptions of the dependent variables appear in the next section.

The treatment variables are entered into the models as a series of three indicator variables, with the war treatment serving as the comparison group. As such, the expectation is that the signs on the treatment coefficients will be negative. The control variables include sociodemographic controls for subject gender (female), age in years, and a series of indicator variables for race (comparison: white/Caucasian), education (comparison: high school degree or less), and family income (comparison: less than \$20,000). They also include political controls using a series of indicator variables for political ideology (comparison: liberal) and news interest (comparison: lowest level).

In addition, the models include two biologically related controls. The first is sex of ideated leader (comparison: neither/either versus male or female), which accounts for the well-known sexual dimorphism related to size in humans. More specifically, evidence dating back three to four million years indicates males have been and continue to be physically larger and stronger than females. ${ }^{110}$ As such, an ideated female leader should be physically smaller than an ideated male leader. The second biologically related control is the socioeconomic status (SES) of the ideated leader. Leaders often emerge from the ranks of social and economic elites, who tend to have greater physical stature because of nutritional advantages they held during their developmental years. ${ }^{111}$ So individuals may simply have learned to expect leaders to possess greater physical stature.

The survey also asked subjects to estimate the education and current income of their ideated leader. While education occurs during a person's developmental years, current income does not. But current income in the United States is often nontrivially associated with household income during childhood, ${ }^{112}$ so it is reasonable to include this measure in the construction of the leader SES variable. Further, estimates using only leader education, which primarily occurs during developmental years, vary inconsequentially from the combined measure. The leader education and leader income variables are ordinal measures that range from 


\section{Physical formidability}

1 , the lowest levels of education and income, to 5 , the highest levels. The leader SES variable is created by taking the mean of the two variables, such that a score of 1 indicates the lowest level of education and lowest level of income and 5 indicates the highest levels of each. Appendix A details all variables, including their descriptive statistics.

\section{Results}

This research tests the assertion that individuals tend to prefer more physically formidable leaders when threat increases. As such, the first two dependent variables are subject estimates of the weight (in pounds) and height (in feet and inches but converted to inches for analysis) of the leader described. Subjects with estimates greater than \pm 3 standard deviations for each measure $(n=16)$ were dropped from the analyses to avoid unrealistic estimates of leaders who, for example, are 9 feet tall or weigh 654 pounds. The expectation is subjects will ideate heavier and taller national leaders in the threat condition (war) than in the nonthreat conditions (peace, cooperation, and control).

The third dependent variable, body mass index (BMI), is a simple weight-for-height index that is widely used by health care professionals as an indicator of body fatness and, therefore, as an initial screen for health problems. ${ }^{113}$ In terms of displays in aggressive communication, ${ }^{72}$ BMI could be considered a performance or endurance display, which conveys the ability of a signaler to exploit an advantage in height or weight. For this research, it is calculated from the leader heights and weights estimated by subjects. The formula is reported in Appendix A. BMI is not a perfect measure of obesity or health, because muscle is heavier than fat. So muscular individuals such as athletes may have a higher BMI but do not carry excessive body fat, while slight individuals such as elderly people who have lost muscle mass may have a lower BMI but do carry excessive body fat. Nonetheless, it is a widely accepted and longstanding measure of health because most people are not athletes or elderly, it is correlated with more precise measures of body fat, and, it usefully predicts risk of disease. ${ }^{114}$

Medical experts categorize BMI results into "underweight" $(<18.5)$, "normal" (18.5 to 24.9$)$, “over- weight" (25.0 to 29.9$)$, and "obese" (> 30.0). A 5'9" tall person weighing less than 125 pounds would be classified as "underweight," while the same person weighing between 125 and 168 pounds would be "normal" weight. On the other hand, someone of that height weighing between 169 and 202 pounds would be "overweight," while at more than 202 pounds the person would be classified as "obese." 113 Individuals at the extremes of BMI are more frail or less vigorous, while individuals in the middle range are likely to be more physically capable of leveraging their physical endowments. The Harvard School of Public Health ${ }^{114}$ reports individuals at extreme levels of BMI are more likely to be at risk for disease, while Puhl and Heuer ${ }^{115}$ report that overweight and obese individuals are often negatively stereotyped as "lazy, unmotivated, lacking in self-discipline, less competent, noncompliant, and sloppy." This is consistent with findings in relation to leadership. Re and colleagues ${ }^{71}$ show that individuals with faces indicating elevated BMI are rated lower in leadership traits. Similarly, Roehling and coauthors ${ }^{18}$ find that obese individuals are less likely to emerge as candidates for political office and, when they do, receive lower absolute vote share and lower relative vote share compared to their more slender opponents. Figure 1 presents silhouettes of average people across a range of BMIs controlling for height. ${ }^{116}$ It shows how a person can reach levels of BMI via changes in weight such that $s$ /he is unlikely to possess the stamina or condition needed to exploit even unusual height. The expectation is that estimates of BMI will be greater under the threat condition than the nonthreat conditions, but not to the point of extreme obesity.

The results of the multivariate analyses support the expectation that individuals tend to prefer leaders with greater physical stature in the threat condition than in the nonthreat conditions. Table 2 summarizes the results through average treatment effects and predicted values derived from the regression models for weight, height, and BMI (see Appendix C). It is important to note that all the signs on the regression coefficients for the treatments are negative, indicating subjects consistently ideated a leader with lesser physical stature in the nonthreat conditions (i.e., peace, cooperation, and control) compared to the threat condition (i.e., war). These models predict that the typical leader ideated in time of war weighed 188.3 pounds, was 72.6 inches tall, and had a BMI of 25.1 (just into the overweight 

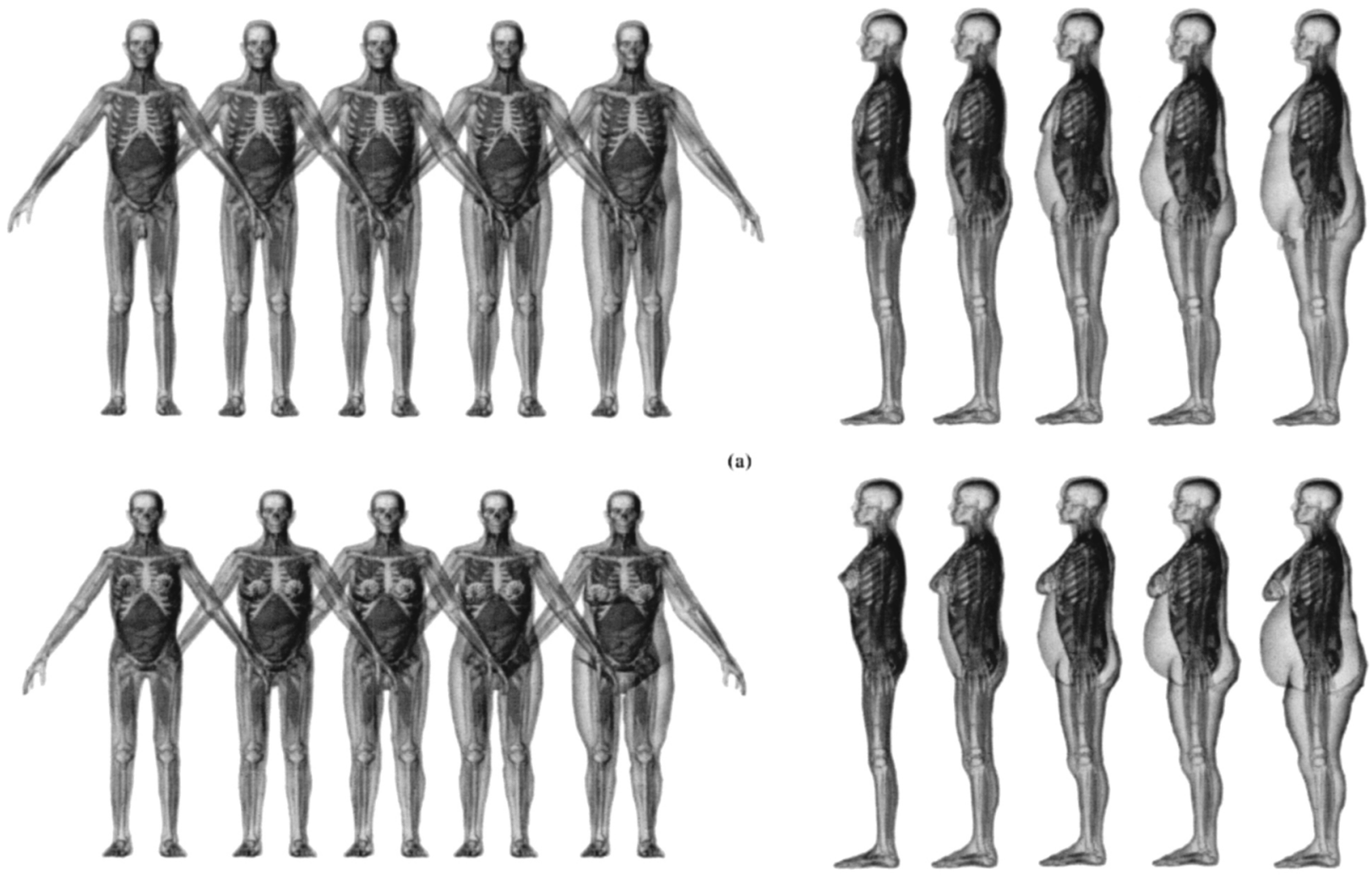

(b)

Figure 1. Male and female silhouettes by BMI. Note: The silhouettes appear in order from lower to higher BMI: normal (23.5), overweight (27.7), obese level-1 (33.3), obese level-2 (37.8), and morbidly obese (45.0) ${ }^{116}$

category), when all covariates are held at their means. The table shows subjects in the war/threat condition ideated a national leader eight pounds heavier, threetenths of an inch taller ( $p=0.08$, one-tailed), and eighttenths of a point larger in BMI than subjects in the peace condition.

The results suggest similar but smaller differences between the war and control conditions, although the difference in height did not achieve a conventional level of statistical significance using a one-tailed test. On the other hand, the differences between the war and cooperation conditions are not statistically discernible for height and BMI, and the difference only reaches a marginal level of statistical significance for weight ( $p=$ 0.07 , one-tailed). While the results for comparisons between the war condition and the peace and control conditions are primarily as expected, the statistical results for the comparison of the war and cooperation conditions are unexpectedly weak. One plausible explanation is that the mention of "national crisis" in the cooperation condition stimulated a threat reaction as well. Because the cooperation condition was not intended to stimulate threat, subjects assigned that treatment did not receive a manipulation check for threat. So this issue remains open for future investigation.

At a certain point, a person can possess excessively large physical proportions that lead to unhealthiness instead of physical formidability. Figure 2 shows the distribution of leader BMIs based on subjects' estimates of leader weight and height placed into the common BMI categories of underweight, normal, overweight, and obese. The flatter distribution (i.e., more negative kurtosis) for the war condition stands out from the more sharply peaked distributions (i.e., more positive kurtosis) for the peace, cooperation, and control conditions. The figure shows that in the war condition subjects were more likely to ideate leaders in 
Table 2. Summary of treatment effects and predicted values, anthropometric measures.

\begin{tabular}{|c|c|c|c|c|c|}
\hline & \multicolumn{3}{|c|}{ Treatment effects } & \multicolumn{2}{|c|}{ Predicted values } \\
\hline & $\begin{array}{c}\text { ATE } \\
\text { (v. War) }\end{array}$ & $S E$ & $p^{*}$ & Value & $S E$ \\
\hline \multicolumn{6}{|l|}{ Weight (pounds) } \\
\hline War & - & - & - & 188.27 & 1.74 \\
\hline Peace & -7.99 & 2.26 & $<0.001$ & 180.28 & 1.49 \\
\hline Cooperation & -3.45 & 2.37 & 0.07 & 184.82 & 1.61 \\
\hline Control & -6.23 & 2.25 & 0.003 & 182.05 & 1.42 \\
\hline \multicolumn{6}{|l|}{ Height (inches) } \\
\hline War & - & - & - & 72.56 & 0.18 \\
\hline Peace & -0.32 & 0.23 & 0.08 & 72.24 & 0.15 \\
\hline Cooperation & -0.07 & 0.25 & 0.39 & 72.49 & 0.18 \\
\hline Control & -0.26 & 0.23 & 0.13 & 72.30 & 0.14 \\
\hline \multicolumn{6}{|l|}{ BMI (score) } \\
\hline War & - & - & - & 25.09 & 0.21 \\
\hline Peace & -0.86 & 0.28 & 0.001 & 24.23 & 0.19 \\
\hline Cooperation & -0.35 & 0.31 & 0.13 & 24.74 & 0.23 \\
\hline Control & -0.63 & 0.28 & 0.01 & 24.46 & 0.18 \\
\hline
\end{tabular}

Note: Dependent variables are subjects' estimates of their ideated leader's weight and height and the leader's resulting BMI. See Appendix C for the full regression models from which these estimates are derived.

"one-tailed test.

the overweight, but not obese, category and less likely to ideate leaders in the normal category. Nearly 45 percent of subjects in the war condition ideated an overweight leader versus a maximum of 36 percent (peace) under the other conditions. On the other hand, nearly 50 percent described a leader in the normal category after the war treatment versus a minimum of 57 percent (cooperation) after the other treatments. It should also be noted that few subjects, regardless of treatment group, described a likely unhealthy underweight (maximum 3 percent in cooperation) or obese leader (maximum 6 percent in war).

The anthropometric models suggest individuals do indeed prefer leaders with greater physical stature under conditions of threat. To confirm the anthropometric results, the questionnaire also asked subjects to assess their ideated leader in terms of a number of nonanthropometric or perceived characteristics. Specifically, it asked subjects to indicate "How well does each word or phrase describe your preferred leader?" coded on a 7-point scale from "not well at all" (1) to "extremely well" (7). Ten characteristics were randomly presented: athletic, attractive, competent, dependable, dominant, friendly, intelligent, physically fit, physically imposing or intimidating, and physically strong. Appendix D presents the bivariate correlations for these measures. Factor analysis with varimax

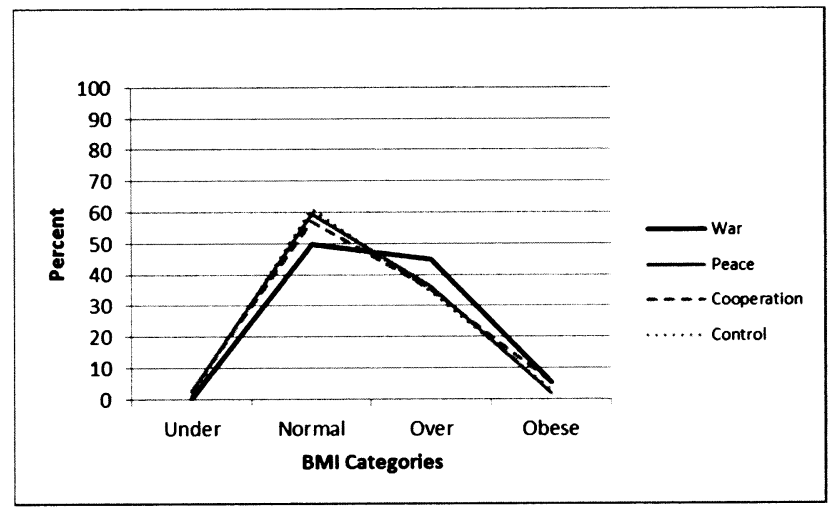

Figure 2. Distribution of BMI categories, by treatment.

rotation yields two factors. The first factor includes competent, dependable, and intelligent, which are characteristics typically found among the commonly held modern leadership prototypes. ${ }^{103,104,105}$ Together these three items build a scale related to prototypical leadership traits with Chronbach's $\alpha=0.91$. The second factor includes athletic, attractive, physically fit, and physically strong. Together these four items build a scale related to physical attractiveness, a physical characteristic frequently found to affect leadership preferences, ${ }^{4,5,6,7,8,9}$ with Chronbach's $\alpha=$ 0.88 . The three remaining items, dominant, friendly, and physically imposing or intimidating, do not load on a factor.

These perceptual measures serve as the second set of dependent variables. The primary expectations are that subjects will ideate a more physically imposing or intimidating leader and a more physically strong leader under conditions of war/threat. The remaining items are analyzed to provide context. Previous research on dominance in facial features suggests subjects will also prefer a more dominant leader under conditions of war/threat, ${ }^{13,64,65}$ although this characteristic is not specifically related to physical characteristics in this study. For instance, an individual could be psychologically but not physically dominant. On the other hand, prototypical leadership traits, by definition, should be desirable regardless of context such that the treatments should not generate differences. Otherwise, physical attractiveness and friendliness have been positively associated with leadership preferences, but it is not 
Table 3. Summary of treatment effects and predicted values, perceptual measures.

\begin{tabular}{|c|c|c|c|c|c|}
\hline & \multicolumn{3}{|c|}{ Treatment effects } & \multicolumn{2}{|c|}{ Predicted values } \\
\hline & $\begin{array}{c}\text { ATE } \\
\text { (v. War) }\end{array}$ & $S E$ & $p^{*}$ & Value & $S E$ \\
\hline \multicolumn{6}{|c|}{ Physically intimidating } \\
\hline War & - & - & - & 4.30 & 0.13 \\
\hline Peace & -0.37 & 0.18 & 0.02 & 3.93 & 0.12 \\
\hline Cooperation & -0.46 & 0.18 & 0.01 & 3.84 & 0.13 \\
\hline Control & -0.44 & 0.18 & 0.01 & 3.86 & 0.12 \\
\hline \multicolumn{6}{|c|}{ Physically strong } \\
\hline War & - & - & - & 5.25 & 0.10 \\
\hline Peace & -0.14 & 0.14 & 0.15 & 5.11 & 0.10 \\
\hline Cooperation & -0.29 & 0.15 & 0.03 & 4.97 & 0.11 \\
\hline Control & -0.21 & 0.14 & 0.07 & 5.04 & 0.10 \\
\hline \multicolumn{6}{|c|}{ Physically attractive } \\
\hline War & - & - & - & 5.18 & 0.08 \\
\hline Peace & -0.04 & 0.11 & 0.37 & 5.14 & 0.08 \\
\hline Cooperation & -0.19 & 0.12 & 0.05 & 4.98 & 0.09 \\
\hline Control & -0.06 & 0.11 & 0.30 & 5.12 & 0.08 \\
\hline \multicolumn{6}{|l|}{ Dominant } \\
\hline War & - & - & - & 5.31 & 0.10 \\
\hline Peace & -0.41 & 0.14 & 0.002 & 4.90 & 0.11 \\
\hline Cooperation & -0.45 & 0.15 & 0.001 & 4.86 & 0.11 \\
\hline \multirow{2}{*}{\multicolumn{6}{|c|}{ Prototypical leadership }} \\
\hline & & & & & \\
\hline War & - & - & - & 6.62 & 0.05 \\
\hline Peace & -0.14 & 0.08 & 0.04 & 6.48 & 0.07 \\
\hline Cooperation & -0.14 & 0.08 & 0.04 & 6.47 & 0.06 \\
\hline Control & -0.12 & 0.08 & 0.07 & 6.50 & 0.06 \\
\hline \multicolumn{6}{|l|}{ Friendly } \\
\hline War & - & - & - & 6.02 & 0.08 \\
\hline Peace & 0.06 & 0.11 & 0.30 & 6.08 & 0.08 \\
\hline Cooperation & 0.01 & 0.12 & 0.48 & 6.03 & 0.09 \\
\hline Control & 0.09 & 0.11 & 0.22 & 6.10 & 0.07 \\
\hline
\end{tabular}

Note: Dependent variables are subjects' ratings of their ideated leader based on the prompt: "How well does each word or phrase describe your preferred leader?" coded on a 7-point scale from "not well at all" (1) to "extremely well" (7). Physically attractive is a 7-point scale constructed from ratings of "athletic," "attractive," "physically fit," and "physically strong." Prototypical leadership is a 7-point scale constructed from ratings of "competent," "dependable," and "intelligent." See Appendix E for the full regression models from which these estimates are derived.

* one-tailed test.

clear from previous research how the experimental conditions should affect those associations, if at all.

Table 3 summarizes the results through average treatment effects and predicted values derived from the perceptual regression models (see Appendix E). Except for the characteristic of friendly, all the signs on the regression coefficients for the treatments again are negative, which indicates subjects consistently ideated a leader with greater physical stature in the war/threat condition. In terms of the physical evaluations, the results clearly indicate substantively and statistically that subjects had a preference for more physically imposing or intimidating leaders under conditions of threat. The predicted score, when all covariates are held at their means, for being physically imposing in the threat condition was 4.3 , while the other conditions range from 3.8 to 3.9. Subjects expressed a substantively similar preference for physically strong leaders under conditions of war, although the statistical effects are weaker. The predicted score for being physically strong under conditions of war was 5.3, while the other conditions range from 5.0 to 5.1. Consistent with the anthropometric results, these analyses suggest conditions of threat stimulate a preference for a more physically formidable leader. On the other hand, subjects only statistically preferred a more physically attractive leader when comparing conditions of war to conditions of cooperation, which suggests the preference for physical formidability under threat is not simply a preference for positive physical characteristics in general.

In terms of nonphysical characteristics, the substantive results and two of the three statistical results suggest subjects tend to prefer a more dominant leader during times of war. The predicted score for dominance under conditions of war was 5.3, while the other conditions range from a statistically discernible 4.9 (peace and cooperation) to a statistically indiscernible 5.2 (control). Contrary to expectations, subjects also expressed a statistically discernible preference for leaders with more prototypical leadership traits under conditions of war. The predicted score for prototypical leadership skills under conditions of war was 6.6 , while the other conditions yielded a score of 6.5. Finally, the treatments do not stimulate any discernible preferences for a friendly leader. Although statistically inconsequential, the positive signs on the treatment coefficients in the friendly model confirm a seemingly commonsensical post hoc argument that people would be least likely to prefer a friendly leader in time of war. In all, the results of the anthropometric and perceptual analyses substantially support the assertion that there is a preference for more physically formidable leaders under conditions of threat.

\section{Discussion}

Most broadly, the objective of this study is to contribute an explanation for the phenomenal preference for leaders with greater physical stature. The theoretical argument proffered here is that followers 


\section{Physical formidability}

prefer leaders with greater physical formidability because of evolutionary adaptations derived from humans' violent ancestral environment. In this environment, individuals who allied with and ultimately followed physically powerful partners were more likely to survive and reproduce because the presence of the physically powerful ally signaled to potential opponents to avoid challenge over important survival and reproductive resources or risk a costly confrontation. This argument suggests threat should stimulate a preference for a more physically formidable leader even in the modern context. Although the effects are not substantively large, the analyses reported in Tables 2 and 3 offer considerable support for this argument. The results clearly indicate threat in the form of war stimulates a preference for leaders with greater weight and a more physically imposing or intimidating stature. They also suggest threat stimulates a preference for leaders with greater BMI and dominance. Further, they provide evidence that threat of war activates a preference for leaders with greater physical strength. On the other hand, preferences for leader height are substantively consistent with the argument but statistically weak.

These results also contribute to the evidence of a consequential relationship between physical attributes and leadership preferences. $3,4,17,19,117,118$ This study advances that literature, particularly in regard to the effects of physical stature on leadership preferences, by using precise anthropometric measures. Unlike previous research that uses images of leaders to estimate weight, height, or BMI, ${ }^{18,70,71,117}$ this study employs actual anthropometric values. One notable difference is that the results presented here show a less reliable effect for height on leadership preferences than other experimental studies. ${ }^{70,71}$ This may suggest the use of heuristics to estimate height (e.g., a face) leads subjects to project characteristics onto images that bias estimates of height. For instance, $\mathrm{Re}$ and colleagues ${ }^{71}$ found that perceived height predicted leadership ratings of an individual, but the actual height of the individual did not.

This study also contributes to the evidence of a preference for more dominant leaders under conditions of threat. ${ }^{13,64,65}$ It advances this literature by extending the domains of comparison beyond war and peace. Van Vugt and Spisak ${ }^{119}$ showed that different leadership preferences emerge under conditions of intergroup competition and intragroup cooperation. In particular, they found that individuals prefer a male leader under conditions of intergroup competition (i.e., outperforming another group on a task) and a female leader under conditions of intragroup cooperation (i.e., maximizing member investment in a group task). This study tested for the effects of intragroup cooperation with the cooperation treatment. While the war treatment stimulated a greater preference among the anthropometric measures for a heavier leader (and not a taller leader or one with greater BMI) than the cooperation treatment, it did stimulate a preference among the perceptual measures for a more physically imposing, strong, and dominant leader than the cooperation treatment. Although these results are mixed, they suggest it may be important for leaders to signal physical formidability to followers and not just potential opponents.

The study's findings raise additional questions. If the evolutionary explanation for physically formidable leaders presented here is correct, these effects should be universal or near-universal. ${ }^{35}$ This study only employs subjects from the United States. Replication is always important in experimental research, but in the case of evolutionary arguments replication across cultures is especially critical to rule out idiosyncratic cultural transmission. Cross-cultural evidence regarding preferences for more dominant ${ }^{13}$ and masculine ${ }^{14,118}$ leaders during time of threat suggests such replications would likely be successful. Another logical question relates to how much threat it takes to stimulate such reactions. For instance, would threat stimulate the preference in situations with less dire consequences than war? In this regard, Murray and Murray ${ }^{120}$ found in a series of studies that military threat was associated with a preference for leaders with greater physical stature but economic threat was not. But that research was primarily concerned with how threat affects preferences regarding the biological sex of leaders.

The argument and findings presented here also raise questions regarding preferences for female versus male leaders. If physical formidability matters in leader preference, and human sexual dimorphism related to size puts women at a disadvantage in terms of physical formidability, ${ }^{110}$ then a preference for physically formidable leaders should result in a preference for male leaders. Indeed, further analyses of these data 
suggest a preference for male over female leaders under threat of war. ${ }^{121}$ This result is consistent with studies of intergroup competition and intragroup cooperation as well as research showing that facial masculinityfemininity affects leadership emergence differently during conditions of war versus peace. ${ }^{14,118,119}$ As noted by one of the anonymous reviewers, these findings raise the possibility that the effects of physical formidability and gender on leadership preferences may converge on the role of testosterone in leadership. Both physical strength and masculinity-femininity are driven by testosterone levels. Male national leaders in particular often make efforts to display physical power (e.g., Ronald Reagan's wood chopping and Vladimir Putin's judo demonstrations). While testosterone affects a number of traits (e.g., empathy), ${ }^{122}$ leaders publicly displaying testosterone-fueled behaviors may intend to project the testosterone-related traits of aggression and dominance to followers and potential opponents. $^{123,124}$

In all, the results support the evolutionary explanation presented here for a connection between physical stature and leadership preferences. The experimental design and highly heterogeneous subject pool drawn from a nationally representative sample bolster confidence in the study's internal and external validity. ${ }^{108}$ This research touches upon a number of issues regarding biological effects on leadership, offering a theoretical basis for understanding the existence of a relationship between leadership and physical stature beyond a basic model of cultural transmission and learning. It implies, therefore, that preference for more physically formidable leaders may be a residual of behavior developed over millennia. If correct, this suggests a bias in a fundamental democratic processleader selection-that is difficult to extinguish. More broadly, this research advances the investigation of biological effects on political behavior, a perspective that is growing but has been neglected for far too long.

\section{References}

1. Richard R. Lau and David P. Redlawsk, "Advantages and disadvantages of cognitive heuristics in political decision making," American Journal of Political Science, 2001, 45(4): 951-971.

2. Lau and Redlawsk, p. 954.

3. Alexander Todorov, Anesu N. Mandisodza, Amir Goren, and Crystal C. Hall, "Inferences of competence from faces predict election outcomes," Science, 2005, 308(5728): 16231626.

4. Susan A. Banducci, Jeffrey A. Karp, Michael Thrasher, and Colin Rallings, "Ballot photographs as cues in lowinformation elections," Political Psychology, 2008, 29(6): 903-917.

5. Niclas Berggren, Henrik Jordahl, and Panu Poutvaara, "The looks of a winner: Beauty and electoral success," Journal of Public Economics, 2010, 94(1-2): 8-15.

6. William Hart, Victor C. Ottati, and Nathaniel D. Krumdick, "Physical attractiveness and candidate evaluation: A model of correction," Political Psychology, 2011, 32(2): 181-203.

7. Anthony C. Little, S. Craig Roberts, Benedict C. Jones, and Lisa M. DeBruine, "The perception of attractiveness and trustworthiness in male faces affects hypothetical voting decisions differently in wartime and peacetime scenarios," Quarterly Journal of Experimental Psychology, 2012, 65(10): 2018-2032.

8. Rodrigo Praino, Daniel Stockemer, and James Ratis, "Looking good or looking competent? Physical appearance and electoral success in the 2008 congressional elections," American Politics Research, 2014, 42(6): 1096-1117.

9. James N. Schubert, Margaret Ann Curran, and Carmen Strungaru, "Physical attractiveness, issue agreement, and assimilation effects in candidate appraisal," Politics and the Life Sciences, 2011, 30(1): 33-49.

10. Gabriel S. Lenz and Chappell Lawson, "Looking the part: Television leads less informed citizens to vote based on candidates' appearance," American Journal of Political Science, 2011, 55(3): 574-589.

11. Kyle Mattes, Michael Spezio, Hackjin Kim, Alexander Todorov, Ralph Adolphs, and R. Michael Alvarez, "Predicting election outcomes from positive and negative trait assessments of candidate images," Political Psychology, 2010, 31(1): 41-58.

12. Jeremy N. Bailenson, Shanto Iyengar, Nick Yee, and Nathan A. Collins, "Facial similarity between voters and candidates causes influence," Public Opinion Quarterly, 2008, 72(5): 935-961.

13. Anthony C. Little, Robert P. Burriss, Benedict C. Jones, and S. Craig Roberts, "Facial appearance affects voting decisions," Evolution and Human Behavior, 2007, 28(1): 18-27.

14. Brian R. Spisak, Peter H. Dekker, Max Krüger, and Mark Van Vugt, "Warriors and peacekeepers: Testing a biosocial implicit leadership hypothesis of intergroup relations using masculine and feminine faces," PLoS ONE, 2012, 7(1): e30399.

15. Stanford W. Gregory, Jr., and Timothy J. Gallagher, 


\section{Physical formidability}

"Spectral analysis of candidates' nonverbal vocal communication: Predicting U.S. presidential election outcomes," Social Psychology Quarterly, 2002, 65(3): 298-308.

16. Casey A. Klofstad, Anderson, Rindy C. and Susan Peters, "Sounds like a winner: Voice pitch influences perception of leadership capacity in both men and women," Proceedings of the Royal Society B: Biological Sciences, 2012, 279(1738): 2698-2704.

17. Cara C. Tigue, Diana J. Borak, Jillian J.M. O’Connor, Charles Schandl, and David R. Feinberg, "Voice pitch influences voting behavior," Evolution and Human Behavior, 2012, 33(3): 210-216.

18. Patricia V. Roehling, Mark V. Roehling, Ashli Brennan, Ashley R. Drew, Abbey J. Johnston, Regina G. Guerra, Ivy R. Keen, Lightbourn, Camerra P. and Alexis H. Sears, "Weight bias in U.S. candidate selection and election," Equality, Diversity and Inclusion, 2014, 33(4): 334-346.

19. Gregg R. Murray and J. David Schmitz, "Caveman politics: Evolutionary leadership preferences and physical stature," Social Science Quarterly, 2011, 92(5): 12151235.

20. Piotr Sorokowski, "Politicians' estimated height as an indicator of their popularity," European Journal of Social Psychology, 2010, 40(7): 1302-1309.

21. Gert Stulp, Abraham P. Buunk, Simon Verhulst, and Thomas V. Pollet, "Tall claims? Sense and nonsense about the importance of height of U.S. presidents," Leadership Quarterly, 2013, 24(1): 159-171.

22. Richard L. Fox and Eric R. A. N. Smith, "Candidate gender and voter choice: Analysis from a multimember preferential voting system," Political Psychology, 1998, 19(2): 405-419.

23. Amy King and Andrew Leigh, "Bias at the ballot box? Testing whether candidates' gender affects their vote," Social Science Quarterly, 2010, 91(2): 324-343.

24. Andrew Leigh and Tirta Susilo, "Is voting skin-deep? Estimating the effect of candidate ballot photographs on election outcomes," Journal of Economic Psychology, 2009, 30(1): 61-70.

25. Robert G. Lord and Cynthia G. Emrich, "Thinking outside the box by looking inside the box: Extending the cognitive revolution in leadership research," Leadership Quarterly, 2000, 11(4): 551-579.

26. Andrew J. King, Dominic D.P. Johnson, and Mark Van Vugt, "The origins and evolution of leadership," Current Biology, 2009, 19(19): R911-R916.

27. Heidi R. Riggio and Ronald E. Riggio, "Appearancebased trait inferences and voting: Evolutionary roots and implications for leadership," Journal of Nonverbal Behavior, 2010, 34(2): 119-125.
28. Chappell Lawson, Gabriel S. Lenz, Andy Baker, and Michael Myers, "Looking like a winner: Candidate appearance and electoral success in new democracies," World Politics, 2010, 62(4): 561-593.

29. Ulrich Rosar, Markus Klein, and Tilo Beckers, "The frog pond beauty contest: Physical attractiveness and electoral success of the constituency candidates at the North RhineWestphalia state election of 2005," European Journal of Political Research, 2008, 47(1): 64-79.

30. Nicholas O. Rule, Nalini Ambady, Reginald B. Adams, Jr., Hiroki Ozono, Satoshi Nakashima, Sakiko Yoshikawa, and Motoki Watabe, "Polling the face: Prediction and consensus across cultures," Journal of Personality and Social Psychology, 2010, 98(1): 1-15.

31. Nicholas O. Rule, Jonathan B. Freeman, Joseph M. Moran, John D. E. Gabrieli, Reginald B. Adams, Jr., and Nalini Ambady, "Voting behavior is reflected in amygdala response across cultures," Social Cognitive and Affective Neuroscience, 2010, 5(2-3): 349-355.

32. John Antonakis and Olaf Dalgas, "Predicting elections: Child's play!” Science, 2009, 323(5918): 1183.

33. Michael L. Spezio, Antonio Rangel, R. Michael Alvarez, John P. O'Doherty, Kyle Mattes, Alexander Todorov, Hackjin Kim, and Ralph Adolphs, "A neural basis for the effect of candidate appearance on election outcomes," Social Cognitive and Affective Neuroscience, 2008, 3(4): 344-352.

34. John Tooby and Leda Cosmides, "Psychological foundations of culture," in The Adapted Mind: Evolutionary Psychology and the Generation of Culture, eds. Jerome $\mathrm{H}$. Barkow, Leda Cosmides, and John Tooby (New York: Oxford University Press, 1995).

35. David M. Buss, "Sex differences in human mate preferences: Evolutionary hypotheses tested in 37 cultures," Behavioral and Brain Sciences, 1989, 12(1): 1-49.

36. Charles Darwin, On the Origin of Species by Means of Natural Selection (London: John Murray, 1859).

37. Gregg R. Murray and J. David Schmitz, "Caveman politics: Evolutionary effects on political preferences," paper presented at the Annual Meeting of the MPSA Annual National Conference (Chicago, IL, 2008).

38. Napoleon A. Chagnon, The Yanomamo (London: Wadsworth, 1997).

39. Azur Gat, "The pattern of fighting in simple, small-scale, prestate societies," Journal of Anthropological Research, 1999, 55(4): 563-583.

40. Bruce M. Knauft, "Reconsidering violence in simple human societies: Homicide among the Gebusi and New Guinea," Current Anthropology, 1987, 28(4): 457-500.

41. Mark Van Vugt, Robert Hogan, and Robert B. Kaiser, 
"Leadership, followership, and evolution," American Psychologist, 2008, 63(3): 182-196.

42. Mark Van Vugt, Dominic D. P. Johnson, Robert B. Kaiser, and Rick O'Gorman, "Evolution and the social psychology of leadership: The mismatch hypothesis," in Leadership at the Crossroads, eds. Donelson Forsyth, George R. Goethals, Crystal L. Hoyt, Michael A. Genovese, Lori C. Han, and Ciulla Joanne B. (New York: Praeger, 2008).

43. Richard W. Wrangham and Dale Peterson, Demonic Males: Apes and the Origins of Human Violence (London: Bloomsbury, 1996).

44. Frans De Waal, Chimpanzee Politics: Power and Sex among Apes (Baltimore, MD: Johns Hopkins University Press, 2007).

45. Magnus Enquist and Olof Leimar, "Evolution of fighting behavior, decision rules and assessment of relative strength," Journal of Theoretical Biology, 1983, 102(3): 387-410.

46. G.A. Parker, "Assessment strategy and the evolution of fighting behavior," Journal of Theoretical Biology, 1974, 47(1): 223-243.

47. Herbert Gintis, Eric Alden Smith, and Samuel Bowles, "Costly signaling and cooperation," Journal of Theoretical Biology, 2001, 213(1): 103-119.

48. Michael E. Price and Mark Van Vugt, "The evolution of leader-follower reciprocity: The theory of service-for-prestige," Frontiers in Human Neuroscience, 2014, 8(363) 1-17.

49. Ernst Mayr, What Evolution Is (New York: Basic Books, 2001).

50. Randolph M. Nesse, "Maladaptation and natural selection," Quarterly Review of Biology, 2005, 80(1): 62-70.

51. Charles Crawford, "Adaptations, environments, and behavior: Then and now," in Foundations of Evolutionary Psychology, eds. Charles Crawford and Dennis Krebs (New York: Lawrence Erlbaum Associates, 2008).

52. Robert Foley, "The adaptive legacy of human evolution: A search for the environment of evolutionary adaptedness," Evolutionary Anthropology, 1995, 4(6): 194-203.

53. John Tooby and Leda Cosmides, "The past explains the present: Emotional adaptations and the structure of ancestral environments," Ethology and Sociobiology, 1990, 11(4-5): $375-424$.

54. S. Boyd Eaton and Melvin Konner, "Paleolithic nutrition: A consideration of its nature and current implications," New England Journal of Medicine, 1985, 312(5): 283-289.

55. S. Boyd Eaton, Beverly I. Strassman, Randolph M. Nesse, James V. Neel, Paul W. Ewald, George C. Williams, Alan B. Weder, Stanley B. Eaton, III, Staffan Lindeberg,
Melvin J. Konner, Iver Mysterud, and Loren Cordain, "Evolutionary health promotion," Preventive Medicine, 2002, 34(2): 109-118.

56. Marcello Spinella, "Evolutionary mismatch, neural reward circuits, and pathological gambling," International Journal of Neuroscience, 2003, 113(4): 503-412.

57. Joseph Henrich and Francisco Gil-White, "The evolution of prestige: Freely conferred deference as a mechanism for enhancing the benefits of cultural transmission," Evolution and Human Behavior, 2001, 22(3): 165-196.

58. Robin Ian MacDonald Dunbar, "Neocortex size as a constraint on group size in primates," Journal of Human Evolution, 1992, 22(6): 469-493.

59. Christopher Boehm, Hierarchy in the Forest: The Evolution of Egalitarian Behavior (Cambridge, MA: Harvard University Press, 1999).

60. Aaron Sell, Liana S. E. Hone, and Nicholas Pound, "The importance of physical strength to human males," Human Nature, 2012, 23(1): 30-44.

61. Akko Kalma, "Hierarchisation and dominance assessment at first glance," European Journal of Social Psychology, 1991, 21(2): 165-181.

62. Aaron Sell, Leda Cosmides, John Tooby, Daniel Sznycer, Christopher von Rueden, and Michael Gurven, "Human adaptations for the visual assessment of strength and fighting ability from the body and face," Proceedings of the Royal Society B: Biological Sciences, 2009, 276: 575-584.

63. Amotz Zahavi and Avishag Zahavi, The Handicap Principle: A Missing Piece of Darwin's Puzzle (New York: Oxford University Press, 1999).

64. Stewart J. McCann, "Height, societal threat, and the victory of margin in presidential elections (1824-1992)," Psychological Reports, 2001, 88(3): 741-742.

65. Daniel E. Re, Lisa M. DeBruine, Benedict C. Jones, and David I. Perrett, "Facial cues to perceived height influence leadership choices in simulated war and peace contexts," Evolutionary Psychology, 2013, 11(1): 89-103.

66. Wayne E. Hensley, "Height as a measure of success in academe," Psychology, 1993, 30(1): 40-46.

67. Daniel M. T. Fessler, Colin Holbrook, and Matthew M. Gervais, "Men's physical strength moderates conceptualizations of prospective foes in two disparate societies," Human Nature, 2014, 25(3): 393-409.

68. Thomas Gregor, "Short People," Natural History, 1979, 88(2): 14-19.

69. Bruce J. Ellis, "The evolution of sexual attraction: Evaluative mechanisms in women," in The Adapted Mind: Evolutionary Psychology and the Generation of Culture, eds. 


\section{Physical formidability}

Jerome H. Barkow, Leda Cosmides, and John Tooby (New York: Oxford University Press, 1995).

70. Nancy M. Blaker, Irene Rompa, Inge H. Dessing, Anne F. Vriend, Channah Herschberg, and Mark Van Vugt, "The height leadership advantage in men and women: Testing evolutionary psychology predictions about the perceptions of tall leaders," Group Processes Intergroup Relations, 2013, 16(1): 17-27.

71. Daniel E. Re, Milena Dzhelyova, Iris J. Holzleitner, Cara C. Tigue, David R. Feinberg, and David I. Perrett, "Apparent height and body mass index influence perceived leadership ability in three-dimensional faces," Perception, 2012, 41(12): 1477-1485.

72. Szabolcs Szamado, "How threat displays work: Speciesspecific fighting techniques, weaponry and proximity risk," Animal Behavior, 2008, 76(5): 1455-1463.

73. Fellicity A. Huntingford and Angela K. Turner, Animal Conflict (London: Chapman \& Hall, 1987).

74. John Archer and David Benson, "Physical aggression as a function of perceived fighting ability and provocation: An experimental investigation," Aggressive Behavior, 2008, 34(1): 9-24.

75. Michael D. Jennions and Patricia R. Y. Backwell, "Residency and size affect fight duration and outcome in the fiddler crab, Uca annulipes," Biological Journal of the Linnean Society, 1996, 57(4): 293-306.

76. Elizabeth A. Archie, Thomas A. Morrison, Charles A. H. Foley, Cynthia J. Moss, and Susan C. Alberts, "Dominance rank relationships among wild female African elephants, Loxodonta africana," Animal Behaviour, 2006, 71: 117-127.

77. T. H. Clutton-Brock, F. E. Guinness, and S. D. Albon, Red Deer: Behaviour and Ecology of Two Sexes (Chicago, IL: University of Chicago Press, 1982).

78. Frans De Waal, Our Inner Ape (New York: Riverhead Books, 2005).

79. J. Heinze and B. Oberstadt, "Worker age, size, and social status in queenless colonies of the ant Leptothorax gredleri," Animal Behaviour, 1999, 58(4): 751-759.

80. William A. Searcy, "Morphological correlates of dominance in captive male red-winged blackbirds," Condor, 1979, 81(4): 417-420.

81. Elizabeth A. Whiteman and Isabelle M. Cote, "Dominance hierarchies in group living cleaning gobies: Causes and foraging consequences," Animal Behaviour, 2004, 67(2): 230-247.

82. Daniel G. Freedman, Human Sociobiology: A Holistic Approach (New York: Free Press, 1979).

83. Donald E. Brown and Y. Chia-Yun, “'Big man' in universalistic perspective" (Unpublished manuscript, Santa Barbara, CA: University of California, Santa Barbara, 1993).

84. Carles Boix and Frances Rosenbluth, "Bones of contention: The political economy of height inequality," American Political Science Review, 2014, 108(1): 1-22.

85. J. Lawrence Angel, The People (Washington, DC: Smithsonian Institution Press, 1971).

86. William A. Haviland, "Stature at Tikal, Guatemala: Implications for ancient Maya demography and social organization," American Antiquity, 1967, 32(3): 316-325.

87. Steffen R. Giessner and Thomas W. Schubert, "High in the hierarchy: How vertical location and judgments of leaders' power are interrelated," Organizational Behavior and Human Decision Processes, 2007, 104(1): 30-44.

88. Jerome S. Bruner and Leo Postman, "Symbolic value as an organizing factor in perception," Journal of Social Psychology, 1948, 27(2): 203-208.

89. William F. Dukes and William Bevan, "Size estimation and monetary value: A correlation," Journal of Psychology, 1952, 34(1): 43-53.

90. Lotte Thomsen, Willem E. Frankenhuis, McCaila IngoldSmith, and Susan Carey, "Big and mighty: Preverbal infants mentally represent social dominance," Science, 2011, 331(6016): 477-480.

91. Colin Holbrook and Daniel M. T. Fessler, "Sizing up the threat: The envisioned physical formidability of terrorists tracks their leaders' failures and successes," Cognition, 2013, 127(1): 46-56.

92. Abigail A. Marsh, Henry H. Yu, Julia C. Schechter, and R.J.R. Blair, "Larger than life: Humans' nonverbal status cues alter perceived size," PLoS ONE, 2009, 4(5): e5707.

93. W. D. Dannenmaier and F. J. Thumin, "Authority status as a factor in perceptual distortion of size," Journal of Social Psychology, 1964, 63(2): 361-365.

94. Rich Masters, Jamie Poolton, and John Van Der Kamp, "Regard and perceptions of size in soccer: Better is bigger," Perception, 2010, 39: 1290-1295.

95. Paul R. Wilson, "Perceptual distortion of height as a function of ascribed academic status," Journal of Social Psychology, 1968, 74(1): 97-102.

96. Linda A. Jackson and Kelly S. Ervin, "Height stereotypes of women and men: The liabilities of shortness for both sexes," Journal of Social Psychology, 1992, 132(4): 433-445.

97. Gert Stulp, Abraham P. Buunk, Simon Verhulst, and Thomas V. Pollet, "High and mighty: Height increases authority in professional refereeing," Evolutionary Psychology, 2012, 10(3): 588-601. 


\section{Murray}

98. Petri Bockerman, Edvard Johansson, Urpo Kiiskinen, and Markku Heliovaara, "The relationship between physical work and the height premium: Finnish evidence," Economics and Human Biology, 2010, 8(3): 414-420.

99. Lars Cernerud, "Height and social mobility," Scandinavian Journal of Social Medicine, 1995, 23(1): 28-31.

100. John S. Gillis, Too Tall, Too Small (Champaign, IL: Institute for Personality and Ability Testing, 1982).

101. Patrik K. E. Magnusson, Finn Rasmussen, and Ulf B. Gyllensten, "Height at age 18 years is a strong predictor of attained education later in life: Cohort study of over 950,000 Swedish men," International Journal of Epidemiology, 2006, 35(3): 658-663.

102. Nicola Persico, Andrew Postelwaite, and Dan Silverman, "The effect of adolescent experience on labor market outcomes: The case of height," Journal of Political Economy, 2004, 112(5): 1019-1053.

103. Olga Epitropaki and Robin Martin, "Implicit leadership theories in applied settings: Factor structure, generalizability, and stability over time," Journal of Applied Psychology, 2004, 89(2): 293-310.

104. Donald R. Kinder, "Presidential character revisited," in Political Cognition, eds. Richard R. Lau and Sears David O. (Hillside, New Jersey: Earlbaum, 1986).

105. Arthur H. Miller, Martin P. Wattenberg, and Oksana Malanchuk, "Schematic assessments of presidential candidates," American Political Science Review, 1986, 80(2): 521540 .

106. Dean Keith Simonton, Greatness: Who Makes History and Why (New York: Guilford, 1994).

107. Philip A. Higham and D. William Carment, "Rise and fall of politicians: The judged height of Broadbent, Mulroney, and Turner before and after the 1988 Canadian federal election," Canadian Journal of Behavioural Science, 1992, 24(3): 404-409.

108. Diana C. Mutz, Population-Based Survey Experiments (Princeton, NJ: Princeton University Press, 2011).

109. U.S. Census Bureau: State and County QuickFacts: USA, "USA." http://quickfacts.census.gov/qfd/states/00000. html, accessed July 28, 2014.

110. David C. Geary, Male, Female: The Evolution of Human Sex Differences (Washington, DC: American Psychological Association, 1998).

111. Phyllis B. Eveleth and James M. Tanner, Worldwide Variations in Human Growth (New York: Cambridge University Press, 1990).

112. Bernt Bratsberg, Knut Red, Oddbjrn Raaum, Robin Naylor, Markus Jäntti, Tor Eriksson, and Eva Österbacka,
"Nonlinearities in intergenerational earnings mobility: Consequences for cross-country comparisons," The Economic Journal, 2007, 117(519): C72-C92.

113. Centers for Disease Control and Prevention, "Healthy Weight: It's Not a Diet, It's a Lifestyle, About BMI for Adults," http://www.cdc.gov/healthyweight/assessing/bmi/ adult_bmi/index.html, accessed May 16, 2014.

114. Harvard School of Public Health, "Why Use BMI?" http://www.hsph.harvard.edu/obesity-prevention-source/ obesity-definition/obesity-definition-full-story/\#references, accessed July 5, 2014.

115. Rebecca M. Puhl and Chelsea A. Heuer, "The stigma of obesity: A review and update," Obesity, 2009, 17(5): 941964.

116. Aiping Ding, Matthew M. Mille, Tianyu Liu, Peter F. Caracappa, and X George Xu, "Extension of RPI-adult male and female computational phantoms to obese patients and a Monte Carlo study of the effect on CT imaging dose," Physics in Medicine and Biology, 2012, 57(9): 2441-2459.

117. Daniel E. Re and David I. Perrett, "The effects of facial adiposity on attractiveness and perceived leadership ability," Quarterly Journal of Experimental Psychology, 2014, 67(4): 676-686.

118. Brian R. Spisak, Astrid C. Homan, Allen Grabo, and Mark Van Vugt, "Facing the situation: Testing a biosocial contingency model of leadership in intergroup relations using masculine and feminine faces," Leadership Quarterly, 2012, 23(2): 273-280.

119. Mark Van Vugt and Brian R. Spisak, "Sex differences in the emergence of leadership during competitions within and between groups," Psychological Science, 2008, 19(9): 854858 .

120. Gregg R. Murray and Susan M. Murray, "Caveman executive leadership: Evolved leadership preferences and biological sex," in Evolutionary Psychology in the Business Sciences, ed. Gad Saad (New York: Springer, 2011).

121. Gregg R. Murray, "Evolutionary theory and preferences for female and male leaders" (Unpublished manuscript, Lubbock, TX: Texas Tech University, 2014).

122. Emma Chapman, Simon Baron-Cohen, Bonnie Auyeung, Rebecca Knickmeyer, Kevin Taylor, and Gerald Hackett, "Fetal testosterone and empathy: Evidence from the Empathy Quotient (EQ) and the 'Reading the Mind in the Eyes' test," Social Neuroscience, 2006, 1(2): 135-148.

123. John Archer, "The influence of testosterone on human aggression," British Journal of Psychology, 1991, 82(1): 128.

124. Allan Mazur and Alan Booth, "Testosterone and dominance in men," Behavioral and Brain Sciences, 1998, 21(3): 353-363. 


\section{Physical formidability}

\section{Appendix A}

\section{Variables}

\section{Dependent variables}

Leader weight: "How much does the leader you described weigh (in pounds)?"

$$
M=183.74, S D=25.11
$$

Leader height: "How tall (in feet and inches) is the leader you described?"

$$
M=72.39, S D=2.94
$$

Leader BMI: $\left(\right.$ weight $/$ height $\left.^{2}\right) \times 703$. Weight is entered in pounds and height in inches. $\quad M=24.62, S D=2.92$

Leader assessments: "How well does each word or phrase describe your preferred leader?" (coded "not well at all," 1, to "extremely well," 7).
a. Athletic
$M=4.87, S D=1.43$
b. Attractive
$M=4.79, S D=1.41$
c. Competent
$M=6.49, S D=1.04$
d. Dependable
$M=6.52, S D=0.98$
e. Dominant
$M=5.06, S D=1.45$
f. Friendly
$M=6.06, S D=1.14$
g. Intelligent
$M=6.54, S D=0.93$
h. Physically fit
$M=5.65, S D=1.31$
i. Physically imposing or intimidating

j. Physically strong

$M=3.98, S D=1.74$

$M=5.09, S D=1.43$

k. Scale of classic leadership traits: competent, dependable, and intelligent

$M=6.51, S D=0.91$

1. Scale of physical attractiveness: athletic, attractive, physically fit, and physically strong

$$
M=5.10, S D=1.18
$$

\section{Independent variables}

Leader sex: "What is the gender of the leader you described?"
-1. Male
0. Skipped
1. Female

$79.10 \%$

$2.69 \%$

$18.21 \%$

Leader education: "What is the highest level of education completed by the leader you described?"

1. High school degree or less

2. High school degree and vocational training

$3.08 \%$

3. Some college

$7.56 \%$

4. College degree

$33.21 \%$

5. Graduate degree
Leader income: "What is the approximate annual income of the leader you described?"
1. less than $\$ 50,000$
$6.15 \%$
2. $\$ 50,000-\$ 84,999$
$5.64 \%$
3. $\$ 85,000-\$ 134,999$
$13.59 \%$
4. $\$ 135,000-\$ 199,999$
$24.23 \%$
5. $\$ 200,000$ or more
$50.38 \%$

Leader socioeconomic status (SES): mean of leader education and leader income

$$
M=4.19, S D=0.91
$$

Subject sex: "Are you male or female?"
0 . Male
$47.18 \%$
1. Female
$52.82 \%$

Age: "In what year were you born?" [calculated in years as 2012 - year of birth]

$$
M=51.64, S D=16.22
$$

Political ideology: "How would you rate each of the following individuals and groups? Yourself."
0 . Liberal
$31.54 \%$
1. Moderate
$22.05 \%$
2. Conservative
$42.05 \%$
99. Not sure
$4.36 \%$

Family income: "Thinking back over the last year, what was your family's annual income?" [ranges broken into quartiles]

1. 1st quartile

$22.82 \%$

2. 2nd quartile $19.49 \%$

3. 3rd quartile $23.85 \%$

4. 4th quartile $24.23 \%$

5. Refused/Not sure

$9.62 \%$

Race/ethnicity: "What racial or ethnic group best describes you?" [single choice]

1. White $73.08 \%$

2. Black or African-American $13.08 \%$

3. Hispanic or Latino $\quad 8.33 \%$

6. Mixed Race $2.18 \%$

99. Other (includes Asian or Asian-American, Native American, and Middle Eastern)

$3.33 \%$

Education: "What is the highest level of education you have completed?"

1. High school degree or less

2. Some college $37.82 \%$

3. 4-year college degree

$34.87 \%$

News Interest: "Some people seem to follow what's going on in government and public affairs most of the time, 
whether there's an election going on or not. Others aren't that interested. Would you say you follow what's going on in government and public affairs ... ?"

4. Most of the time

$54.23 \%$

3. Some of the time

2. Only now and then

$12.31 \%$

1. Hardly at all

$5.51 \%$

99. Refused/Not Sure

\section{Appendix B}

\section{Experimental vignettes}

1. War

Imagine that your country is experiencing a time of ongoing war with neighboring countries that suggests its long-term survival is at risk. Create in your mind the national leader of your country, such as a president or prime minister, whom you would want to lead the country during a time of war. This should not be a real person but should be a fictitious person who has all the characteristics and qualities you want in the leader of your country during a time of war.

\section{Peace}

Imagine that your country is experiencing a time of ongoing peace with neighboring countries that suggests its long-term survival is not at risk. Create in your mind the national leader

of your country, such as a president or prime minister, whom you would want to lead the country during a time of peace. This should not be a real person but should be a fictitious person who has all the characteristics and qualities you want in the leader of your country during a time of peace.

\section{Group Cooperation}

Imagine that your country has experienced a major natural disaster that has completely cut the supply of electricity to several million people in a number of large cities across the country. A major, nationwide cooperative effort by citizens to reduce electricity consumption is required until power can be restored to the cities. Create in your mind the national leader of your country, such as a president or prime minister, whom you would want to lead the country in this nationwide cooperative effort. This should not be a real person but should be a fictitious person who has all the characteristics and qualities you want in the leader of your country during this major, nationwide cooperative effort.

\section{Control}

Create in your mind the national leader of your country, such as a president or prime minister, whom you would want to lead the country. This should not be a real person but should be a fictitious person who has all the characteristics and qualities you want in the leader of your country. 
Appendix C

Table 1. OLS models of anthropometric measures of ideated leader.

\begin{tabular}{|c|c|c|c|c|c|c|c|c|c|}
\hline \multirow[b]{3}{*}{ Treatment } & \multicolumn{3}{|c|}{ Weight } & \multicolumn{3}{|c|}{ Height } & \multicolumn{3}{|c|}{ BMI } \\
\hline & Coef. & \multicolumn{2}{|l|}{$S E$} & Coef. & \multicolumn{2}{|l|}{$S E$} & Coef. & \multicolumn{2}{|l|}{$S E$} \\
\hline & & & & & & & & & \\
\hline Peace & -7.99 & 2.26 & $* * *$ & -0.32 & 0.23 & + & -0.86 & 0.28 & $* *$ \\
\hline Cooperation & -3.45 & 2.37 & + & -0.07 & 0.25 & & -0.35 & 0.31 & \\
\hline Control & -6.23 & 2.25 & $* *$ & -0.26 & 0.23 & & -0.63 & 0.28 & * \\
\hline \multicolumn{10}{|l|}{ Leader sex } \\
\hline Male & 6.04 & 3.28 & $*$ & 1.34 & 0.53 & $* *$ & -0.13 & 0.43 & \\
\hline Female & -25.18 & 3.92 & $* * *$ & -2.69 & 0.60 & $* * *$ & -1.81 & 0.52 & $* * *$ \\
\hline Leader SES & -0.96 & 1.17 & & 0.70 & 0.12 & $* * *$ & -0.64 & 0.16 & $* * *$ \\
\hline Female subject & -0.74 & 1.64 & & -0.23 & 0.17 & + & 0.14 & 0.21 & \\
\hline Age & 0.00 & 0.06 & & 0.01 & 0.01 & $*$ & -0.01 & 0.01 & \\
\hline \multicolumn{10}{|l|}{ Ideology } \\
\hline Moderate & 0.89 & 2.10 & & -0.43 & 0.23 & $*$ & 0.42 & 0.28 & + \\
\hline Conservative & 3.20 & 1.95 & + & -0.02 & 0.20 & & 0.43 & 0.25 & $*$ \\
\hline Missing & -1.04 & 4.57 & & -0.10 & 0.40 & & -0.14 & 0.59 & \\
\hline \multicolumn{10}{|l|}{ Income } \\
\hline Quartile 2 & 0.79 & 2.55 & & -0.05 & 0.29 & & 0.13 & 0.34 & \\
\hline Quartile 3 & -0.25 & 2.49 & & 0.02 & 0.27 & & -0.07 & 0.33 & \\
\hline Quartile 4 & 4.28 & 2.58 & * & 0.05 & 0.27 & & 0.53 & 0.32 & $*$ \\
\hline Missing & 0.08 & 3.33 & & -0.32 & 0.33 & & 0.23 & 0.43 & \\
\hline \multicolumn{10}{|l|}{ Race/ethnicity } \\
\hline Black & 2.40 & 3.00 & & 0.06 & 0.28 & & 0.33 & 0.39 & \\
\hline Hispanic & -2.27 & 2.99 & & 0.09 & 0.36 & & -0.27 & 0.40 & \\
\hline Multiple & -3.63 & 4.06 & & 0.49 & 0.57 & & -0.79 & 0.65 & \\
\hline Missing & -0.57 & 4.05 & & 0.39 & 0.51 & & -0.28 & 0.47 & \\
\hline \multirow{2}{*}{\multicolumn{10}{|c|}{ Education }} \\
\hline Some college & -0.74 & 2.33 & & -0.49 & 0.23 & $*$ & & & \\
\hline 4-yr degree & -1.85 & 2.17 & & -0.43 & 0.24 & $*$ & 0.03 & 0.27 & \\
\hline \multicolumn{10}{|l|}{ News interest } \\
\hline Now and then & -0.65 & 4.44 & & 0.26 & 0.47 & & -0.27 & 0.61 & \\
\hline Sometimes & -0.35 & 3.88 & & 0.41 & 0.43 & & -0.30 & 0.57 & \\
\hline Most time & -0.95 & 3.97 & & 0.43 & 0.43 & & -0.41 & 0.57 & \\
\hline Missing & -9.87 & 10.72 & & -1.34 & 0.78 & $*$ & -0.25 & 1.59 & \\
\hline Constant & 191.58 & 7.20 & $* * *$ & 68.66 & 0.88 & $* * *$ & 28.32 & 1.00 & $* * *$ \\
\hline$N$ & 780 & & & 780 & & & 780 & & \\
\hline$F$ & 9.13 & $<0.001$ & & 16.78 & $<0.001$ & & 3.39 & $<0.001$ & \\
\hline$R^{2}$ & 0.27 & & & 0.42 & & & 0.11 & & \\
\hline Root MSE & 21.79 & & & 2.28 & & & 2.80 & & \\
\hline
\end{tabular}

$* p<0.05 * p<0.01 * * p<0.001+p<0.10$ (one-tailed) 


\section{Appendix D}

Table 1. Bivariate correlations of measures of ideated leader.

\begin{tabular}{|c|c|c|c|c|c|c|c|c|c|c|c|c|c|c|c|}
\hline Leader characteristics & 1 & 2 & 3 & 4 & 5 & 6 & 7 & 8 & 9 & 10 & 11 & 12 & 13 & 14 & 15 \\
\hline 1 Weight & & & & & & & & & & & & & & & \\
\hline 2 Height & $0.54^{*}$ & & & & & & & & & & & & & & \\
\hline $3 \mathrm{BMI}$ & $0.81 *$ & -0.04 & & & & & & & & & & & & & \\
\hline 4 Athletic & $0.07^{*}$ & $0.21^{*}$ & -0.06 & & & & & & & & & & & & \\
\hline 5 Attractive & 0.02 & $0.08^{*}$ & -0.03 & $0.57^{*}$ & & & & & & & & & & & \\
\hline 6 Competent & 0.02 & $0.14 *$ & $-0.07^{*}$ & $0.19^{*}$ & $0.24^{*}$ & & & & & & & & & & \\
\hline 7 Dependable & 0.01 & $0.08^{*}$ & -0.05 & $0.19^{*}$ & $0.26^{*}$ & $0.79 *$ & & & & & & & & & \\
\hline 8 Dominant & $0.14^{*}$ & $0.10^{*}$ & $0.10^{*}$ & $0.34^{*}$ & $0.38^{*}$ & $0.26^{*}$ & $0.26^{*}$ & & & & & & & & \\
\hline 9 Friendly & -0.04 & 0.05 & $-0.07 *$ & $0.32 *$ & $0.37^{*}$ & $0.51^{*}$ & $0.53 *$ & $0.21 *$ & & & & & & & \\
\hline 10 Intelligent & 0.00 & $0.14^{*}$ & $-0.10^{*}$ & $0.22 *$ & $0.26^{*}$ & $0.83^{*}$ & $0.74^{*}$ & $0.28 *$ & $0.52 *$ & & & & & & \\
\hline 11 Physically fit & 0.02 & $0.19^{*}$ & $-0.10^{*}$ & $0.65^{*}$ & $0.55^{*}$ & $0.43^{*}$ & $0.38 *$ & $0.34^{*}$ & $0.44^{*}$ & $0.45^{*}$ & & & & & \\
\hline 12 Physically imposing & $0.20^{*}$ & $0.16^{*}$ & $0.13^{*}$ & $0.39 *$ & $0.33^{*}$ & -0.02 & 0.04 & $0.48^{*}$ & 0.02 & 0.02 & $0.27^{*}$ & & & & \\
\hline 13 Physically strong & $0.11^{*}$ & $0.22^{*}$ & -0.02 & $0.65^{*}$ & $0.57^{*}$ & $0.25^{*}$ & $0.26^{*}$ & $0.42 *$ & $0.38^{*}$ & $0.31 *$ & $0.68^{*}$ & $0.43^{*}$ & & & \\
\hline 14 SES (scale) & 0.06 & $0.32 *$ & $-0.16^{*}$ & $0.14^{*}$ & $0.10^{*}$ & $0.25^{*}$ & $0.20^{*}$ & $0.10^{*}$ & $0.10^{*}$ & $0.30 *$ & $0.22 *$ & -0.02 & $0.08^{*}$ & & \\
\hline 15 Attractive (scale) & 0.06 & $0.20^{*}$ & -0.06 & $0.86^{*}$ & $0.80 *$ & $0.32 *$ & $0.32 *$ & $0.44^{*}$ & $0.45^{*}$ & $0.37^{*}$ & $0.85^{*}$ & $0.43^{*}$ & $0.86^{*}$ & $0.15^{*}$ & \\
\hline 16 Leadership (scale) & 0.02 & $0.13^{*}$ & $-0.08^{*}$ & $0.22 *$ & $0.27^{*}$ & $0.94^{*}$ & $0.91^{*}$ & $0.29^{*}$ & $0.57^{*}$ & $0.92^{*}$ & $0.45^{*}$ & 0.02 & $0.30^{*}$ & $0.27^{*}$ & $0.36^{*}$ \\
\hline
\end{tabular}




\section{Physical formidability}

\section{Appendix E}

Table 1. OLS models of perceptual measures of ideated leader.

\begin{tabular}{|c|c|c|c|c|c|c|c|c|c|c|c|c|c|c|c|c|c|c|}
\hline & \multicolumn{3}{|c|}{$\begin{array}{l}\text { Physically } \\
\text { imposing }\end{array}$} & \multicolumn{3}{|c|}{$\begin{array}{l}\text { Physically } \\
\text { strong }\end{array}$} & \multicolumn{3}{|c|}{$\begin{array}{l}\text { Physically } \\
\text { attractive }\end{array}$} & \multicolumn{3}{|c|}{ Dominant } & \multicolumn{3}{|c|}{$\begin{array}{l}\text { Prototypical } \\
\text { leadership }\end{array}$} & \multicolumn{3}{|c|}{ Friendly } \\
\hline & Coef. & $S E$ & & Coef. & $S E$ & & Coef. & $S E$ & & Coef. & $S E$ & & Coef. & $S E$ & & Coef. & $S E$ & \\
\hline \multicolumn{19}{|l|}{ Treatment } \\
\hline Peace & 0.37 & 0.18 & $*$ & -0.14 & 0.14 & & -0.04 & 0.11 & & -0.41 & 0.14 & $* *$ & -0.14 & 0.08 & $*$ & 0.06 & 0.11 & \\
\hline Cooperation & -0.46 & 0.18 & $* *$ & -0.29 & 0.15 & $*$ & -0.19 & 0.12 & + & -0.45 & 0.15 & $* *$ & -0.14 & 0.08 & $*$ & 0.01 & 0.12 & \\
\hline Control & -0.44 & 0.18 & $* *$ & -0.21 & 0.14 & + & -0.06 & 0.11 & & -0.13 & 0.14 & & -0.12 & 0.08 & + & 0.09 & 0.11 & \\
\hline \multicolumn{19}{|l|}{ Leader sex } \\
\hline Male & 0.09 & 0.40 & & 0.34 & 0.36 & & -0.04 & 0.29 & & 0.05 & 0.27 & & -0.16 & 0.15 & & -0.08 & 0.27 & \\
\hline Female & -0.48 & 0.43 & & -0.40 & 0.38 & & -0.53 & 0.31 & $*$ & -0.26 & 0.29 & & -0.15 & 0.17 & & -0.10 & 0.29 & \\
\hline Leader SES & -0.04 & 0.08 & & 0.14 & 0.07 & $*$ & 0.20 & .06 & $* * *$ & 0.19 & 0.07 & $* *$ & 0.22 & 0.05 & $* * *$ & 0.15 & .06 & $* *$ \\
\hline Fer & -0.17 & 0.13 & & 0.44 & 0.11 & $* * *$ & 0.30 & .09 & $* * *$ & 0.09 & 0.11 & & 0.11 & 0.07 & * & 0.27 & 0.09 & $* *$ \\
\hline Age & -0.01 & 0.00 & & 0.01 & 0.00 & $* *$ & 0.01 & 0.00 & $* * *$ & -0.01 & 0.00 & $*$ & 0.00 & 0.00 & + & 0.01 & 0.00 & * \\
\hline \multicolumn{19}{|l|}{ deology } \\
\hline Moderate & -0.15 & 0.18 & & -0.16 & 0.14 & & -0.17 & 0.11 & + & -0.12 & 0.15 & & -0.18 & 0.08 & $*$ & -0.18 & 0.11 & + \\
\hline & 0.08 & 0.16 & & -0.04 & 0.12 & & -0.15 & .10 & + & 0.10 & 0 & & -0.13 & 0.08 & $*$ & -0.20 & .10 & $*$ \\
\hline Miss & 0.39 & 0.33 & & -0.24 & 0.28 & & -0.35 & 0.26 & + & 0.28 & 0.26 & & -0.45 & 0.24 & $*$ & -0.22 & 0.25 & \\
\hline \multicolumn{19}{|l|}{ ncome } \\
\hline & 0.27 & 0.21 & & -0.22 & 0.16 & + & -0.06 & 0.12 & & -0.35 & 0.17 & $*$ & -0.21 & 0.11 & $*$ & -0.38 & 0.13 & $* *$ \\
\hline & 0.03 & 0.19 & & -0.20 & 0.15 & + & -0.07 & 0.12 & & -0.26 & 16 & $*$ & -0.12 & 0.09 & & -0.40 & 12 & $* 2$ \\
\hline Q & -0.03 & 0.20 & & -0.31 & 0.16 & $*$ & -0.18 & 0.13 & + & -0.20 & 0.15 & + & -0.13 & 0.09 & + & -0.38 & 0.13 & $* *$ \\
\hline Miss & -0.14 & 0.24 & & -0.42 & 0.19 & $*$ & -0.25 & 0.16 & + & -0.62 & 0.20 & $* *$ & -0.21 & 0.13 & + & -0.39 & 0.16 & $* *$ \\
\hline \multicolumn{19}{|l|}{ Race/ethnicity } \\
\hline & 9 & 0.22 & * & 0 & 0.15 & $* *$ & 0.57 & .12 & $* * *$ & 0.43 & 0.17 & $* *$ & -0.11 & 0.10 & & 0.09 & 0.13 & \\
\hline & & 0.22 & + & -0.07 & 0.18 & & -0.14 & 0.17 & & 0.16 & 0.20 & & -0.27 & 0.14 & $*$ & -0.18 & 18 & \\
\hline & 0.56 & 0.36 & + & -0.03 & 0.31 & & 0.13 & 0.25 & & -0.04 & 0.3 & & 0.32 & 0.12 & $* *$ & 0.75 & 0.14 & $*$ \\
\hline Missing & 0.54 & 0.27 & $*$ & -0.08 & 0.22 & & -0.10 & 0.18 & & -0.18 & 0.21 & & -0.24 & 0.16 & + & -0.25 & 0.22 & \\
\hline \multicolumn{19}{|l|}{ Education } \\
\hline So & -0.25 & 0.17 & + & -0.03 & 0.13 & & 0.03 & 0.10 & & 0.12 & 0 . & & 0.12 & 0.09 & + & 0.01 & 0.10 & \\
\hline 4-yr degree & -0.21 & 0.18 & & -0.29 & 0.14 & $*$ & -0.17 & 0.12 & + & 0.17 & 0.1 & & 0.19 & 0.09 & $*$ & -0.11 & 0.11 & \\
\hline \multicolumn{19}{|l|}{ News interest } \\
\hline Now and then & -0.36 & 0.31 & & 0.03 & 0.27 & & -0.19 & 0.21 & & -0.34 & 0.2 & & 0.24 & 0.21 & & 0.42 & 0.23 & $*$ \\
\hline & -0.09 & 0.30 & & -0.11 & 0.26 & & -0.19 & 0.19 & & -0 & 02 & & 0.13 & 0.20 & & 0.18 & 0.23 & \\
\hline $\mathrm{N}$ & -0.27 & 0.30 & & -0.16 & 0.27 & & -0.31 & 0.20 & + & -0.35 & 0.28 & & 0.24 & 0.20 & & 0.35 & 0.23 & + \\
\hline & -0.05 & 0.64 & & -0.21 & 0.56 & & -0.53 & 0.44 & & -0.06 & 0.58 & & -0.59 & 0.39 & + & -0.15 & 0.57 & \\
\hline Constant & 5.01 & 0.62 & $* * *$ & 4.16 & 0.56 & $* * *$ & 4.27 & 0.45 & $*$ & 5.14 & 0.51 & * & 5.58 & 0.36 & $* * *$ & 5.23 & 0.45 & \\
\hline$N$ & 760 & & & 762 & & & 776 & & & 761 & & & 775 & & & 761 & & \\
\hline$F$ & \multicolumn{3}{|c|}{$2.09<0.001$} & \multicolumn{3}{|c|}{$3.94<0.001$} & \multicolumn{3}{|c|}{$4.23<0.001$} & \multicolumn{3}{|c|}{$2.78<0.001$} & \multicolumn{3}{|c|}{$3.88<0.001$} & \multicolumn{3}{|c|}{$3.14<0.001$} \\
\hline$R^{2}$ & \multicolumn{2}{|l|}{0.06} & & 0.12 & & & 0.13 & & & 0.08 & & & 0.15 & & & 0.08 & & \\
\hline Root MSE & 1.71 & & & 1.36 & & & 1.12 & & & 1.41 & & & 0.86 & & & 1.11 & & \\
\hline
\end{tabular}

${ }^{*} p<0.05 * * p<0.01 * * * p<0.001+p<0.10$ (one-tailed) 